\title{
A WEBQUEST COMO ATIVIDADE DIDÁTICA POTENCILIZADORA DA EDUCAÇÃO
}

Fernanda Quaresma da Silva, UNIMINAS - fernandalauper@gmail.com

Hélio Oliveira Ferrari, UNIMINAS - gandhiferrari@gmail.com

\section{RESUMO}

O presente artigo retrata as Tecnologias de Informação e Comunicação e a forma com que têm impactado na nossa cultura e costumes. Apresenta uma atividade didática a Webquest, suas potencialidades e um exemplo da mesma que foi utilizado em laboratório de informática educativa como recurso pedagógico. Traz informações referentes a diversos autores que contribuem para a compreensão das tecnologias e como estas podem agregar ao cotidiano escolar. Sendo assim, o objetivo deste artigo é apresentar esta metodologia, seus recursos e um modelo utilizado pelos autores em uma escola.

Palavras-chave: Educação; Tecnologias de Informação e Comunicação; Webquest.

\begin{abstract}
The goal of this paper is to demonstrate the way which Information and Communication Technologies have impacted on our culture and customs. A activity WebQuest is presented and used in the computer lab like potential resource teaching. Get information about the various authors contributing to the understanding of technology and how they can add to school everyday. Therefore, the aim of this paper is to present this methodology, its resources and a model used by authors in a school.
\end{abstract}

Keywords: Education, Information and Communication Technologies, Webquest

\section{Introdução}

Muito tem-se falado em tecnologias nos tempos atuais e em como esta tem auxiliado muitos educadores, além de ter-se tornado cada vez mais atrativa. O termo novas tecnologias é muito bem definido por Masetto (2006 p. 146), quando diz que "denominamos novas tecnologias aquelas que estão vinculadas ao uso do computador, à informática, à telemática e à educação à distância". Diante deste contexto, nos tempos atuais buscam-se educadores cada vez mais habilitados e familiarizados com as novas tecnologias. Trabalhar de forma lúdica, dinâmica e atrativa, torna o conteúdo e as aulas muito mais interessantes tanto para os alunos, quanto para os educadores. A busca de recursos tecnológicos para mediação pedagógica não se resume a qualquer metodologia disponível, pois antes deve-se pensar de forma crítica e reflexiva sobre quais metodologias utilizar e o que estas podem oferecer. Esta busca pode se tornar um momento de grande aprendizado para o educador(a) inovador(a) e não resistente às tecnologias de informação e comunicação, ou seja, o educador que permite a abertura de um mundo de possibilidades.

Nota-se ainda que não precisamente, o(a) educador(ra) irá aprender todas as 
tecnologias e mais ainda gostar delas, mas que conhecerá, se familiarizará e muitas vezes até compreenderá. Moran (1995) afirma que "as tecnologias de comunicação não mudam necessariamente a relação pedagógica. As tecnologias tanto servem para reforçar uma visão conservadora individualista como uma visão progressista". Muitas vezes em alguns contextos educacionais educadores utilizam tecnologias em suas aulas, de forma coerciva e excludente, não permitindo ao aluno a manipulação autônoma dos computadores, criando assim um amedrontamento, diferente do educador aberto a esse mundo de possibilidades, que utiliza estes recursos como forma de agregar potencialidade a suas aulas. Há várias mídias disponíveis na internet e muitos sites apresentam explicitamente informações e contextos nem sempre educativos. Sendo assim o(a) educador(a) como mediador(a) pedagógico(a) é responsável por selecionar quais tecnologias de informação e comunicação são mais adequadas ao contexto educativo em que se envolve e adequar esses recursos com a didática e a metodologia do ambiente educacional. Percebe-se que não é fácil para educadores, receberem todas essas mudanças com tranqüilidade, como Masetto (2006) afirma:

(...) confiar no aluno; acreditar que ele é capaz de assumir a responsabilidade pelo seu processo de aprendizagem junto conosco; assumir que o aluno, apesar de sua idade, é capaz de retribuir atitudes adultas de respeito, de diálogo, de responsabilidades, de arcar com as consequiências de seus atos (...) todos esses comportamentos exigem, certamente, uma mudança de mentalidades, de valores e de atitudes de nossa parte. (MASETTO, 2006, p. 142).

Essa mudança de valores, mentalidade e atitudes não é simples, mas é fundamental. Os profissionais da educação que aceitaram essas mudanças e que hoje apresentam suas conquistas, muito têm auxiliado outros educadores, motivando na busca e na superação dessas barreiras. Em meio a todas as novas tecnologias uma metodologia muito interessante é a Webquest (WQ). Esse termo foi concebido pelo professor Bernie Dodge em 1995, mesmo ano em que o Brasil teve acesso comercial a internet. A proposta metodológica é a de uma atividade orientada e investigativa de maneira que o assunto abordado seja apresentado de forma criativa. A cooperação faz parte desta proposta onde todos os envolvidos trocam informações e experiências ao utilizar a WQ. De acordo com Dodge (1995) "aprendizagens significativas são resultados de atos de cooperação, as WQs estão baseadas na convicção de que aprendemos mais e melhor com os outros do que sozinhos."

Diversas teorias de aprendizagem associadas à metodologia Webquest podem tornar esta ainda mais relevante. Quando Dodge (1995) afirma que aprendemos melhor com os outros do que sozinhos percebemos que a teoria sócio-interacionista muito tem a contribuir para a Webquest. O trabalho colaborativo que permite a troca e a aquisição de novos conhecimentos permite uma aprendizagem muito mais significativa e interessante. Cabe aos educadores utilizarem a Webquest de maneira que esta além de suas extensas possibilidades permitem aos alunos o trabalho em grupo e a troca de saberes entre os participantes, fator imprescindível da teoria sócio-interacionista. Os professores além de se tornarem autores de sua criação, tem a chance de desenvolver ainda mais a sua criatividade e percepção ao adequar o conteúdo disciplinar ao Ambiente Virtual de Aprendizagem - AVA.

Percebe-se através de estudos bibliográficos e experiências vivenciadas que a WQ como recurso tecnológico didático tem contribuído imensamente para a 
aprendizagem significativa, acredita-se que isto se deve ao fato da mesma oportunizar um AVA criativo, significativo e adequado para a utilização da internet, além de orientar os alunos na busca pelo tema apresenta todas as informações necessárias a esta busca. Sendo assim o objetivo deste artigo foi apresentar esta metodologia, seus recursos e um modelo utilizado na escola Oficina do Saber em Uberlândia. Pretende-se ainda, demonstrar o quanto esta metodologia pode potencializar o processo de ensinoaprendizagem e levar atratividade ao se trabalhar com informática educativa.

\section{2. $O$ conceito Webquest}

Dentre todas as pesquisas bibliográficas que foram realizadas sobre o tema Webquest, a preferência foi pelas definições de duas autoras que já vem trabalhando com o tema há alguns anos, Celina Abar e Lisbete Barbosa (2008). De acordo com Celina e Lisbete (2008), a Webquest é uma atividade didática estruturada de forma que os alunos se envolvam no desenvolvimento de uma tarefa de investigação usando principalmente recursos da internet. Esta foi proposta por Bernie Dodge, professor da San Diego State University em 1995. Dodge preparou uma tarefa para alunos de um curso de capacitação de professores onde eles deveriam adquirir informações a respeito de um software educacional. Foi estruturada de maneira que estes alunos tivessem acesso a sites da internet previamente designados por ele. De acordo com as autoras Celina e Lisbete (2008): "A tecnologia Webquest é sustentada por teorias psicopedagógicas, podendo ser caracterizada como técnica de aprendizagem construtivista, que pode ser utilizada em um ambiente construcionista". O aluno constrói o seu próprio conhecimento a partir do momento em que manipula o computador utilizando o ambiente virtual de aprendizagem - AVA Webquest.

\subsection{Estrutura de uma Webquest}

A Webquest possui uma estrutura ao que contém sete tópicos, mais uma vez apresento à definição de Lisbete e Celina (2008, p. 21-35):

Introdução: esta deve apresentar o assunto de maneira breve e propor questões que irão fundamentar o processo investigativo. Deve-se despertar a curiosidade dos alunos em relação ao tema trabalhado.

Tarefa: a tarefa ${ }^{1}$ evoca uma ação, o que é para fazer. Deve propor de forma clara a elaboração de um produto criativo que entusiasme, motive e desafie os alunos.

Processo: descreve como os alunos irão caminhar para desenvolver a Tarefa e orientá-lo no procedimento fazem parte das informações que precisam estar presentes no Processo e nos Recursos. O processo descreve passo-a-passo a dinâmica da atividade, e os Recursos são informações que permitem concretizar a Tarefa.

Avaliação: deve apresentar aos alunos, com clareza, como o resultado da Tarefa será avaliado e que fatores serão considerados indicativos de que ela foi concluída com sucesso. Tais critérios devem estar claramente estabelecidos e de acordo com os seus objetivos.

Conclusão: a conclusão resume o propósito geral do que foi aprendido e sinaliza como o aluno poderá continuar a estudar o assunto. Deve ser um convite para aprender

1 Dodge definiu possíveis tarefas para a webquest, estas são detalhadas no livro - Webquest um desafio para o professor: uma solução inteligente para o uso da internet. Das autoras Celina A. A. Abar e Lisbete Madsen Barbosa. Editora: Avercamp, 2008. 
mais.

Créditos: estes podem trazer referências aos autores da Webquest, escola em que foi elaborada, nível de escolaridade ou faixa etária a quem se destina, fontes das figuras ou textos utilizados, data da elaboração ou atualização e outras informações que possam ser úteis a quem for utilizá-la.

Esta estrutura tem a razão de ser: a atividade executada pelos alunos possui as características de um projeto em que, em primeiro lugar, surge a idéia; em seguida, definem-se os objetivos do projeto; faz-se o plano das ações que devem ser executadas; e apresentam-se os recursos e fontes necessárias à execução das ações. (LISBETE e CELINA, 2008, p. 17)

Todos esses tópicos são fundamentais para que a WQ siga os padrões sugeridos por Dodge, porém de acordo com o tema a ser trabalhado esta pode ser adaptada. A Webquest construída pela autora foi adaptada de acordo com a proposta da mesma, estas mudanças são apresentadas no tópico 3 deste artigo. Apresenta-se a seguir alguns passos para a elaboração de uma Webquest.

\subsection{Elaboração de uma Webquest}

$\mathrm{O}$ site Senac $\mathrm{SP}^{2}$ apresenta alguns passos para elaboração de uma Webquest, são eles:

a. Planejar - O planejamento é o aspecto pedagógico da elaboração. É o momento de definir o conteúdo da webquest. É uma etapa de criação, que demanda tempo e reflexão, e não exige o uso do computador. A seguir alênca-se um pequeno roteiro de elaboração da WQ:

b. Formatar - A formatação é o aspecto editorial da elaboração. É o momento de inserir o conteúdo (definido na etapa de planejamento) num gabarito que contém as seções típicas de uma WQ: Introdução, Tarefa, Processo, fontes de informação, Avaliação, Conclusão. Nessa etapa, vale incluir imagens, revisar e dar acabamento na webquest.

c. Publicar - Publicar significa pôr a webquest no ar. É o momento de tomar as providências técnicas para que a webquest possa ser acessada e utilizada pelas pessoas, na Internet.

Para orientá-lo no processo de elaboração, apresenta a seguir um roteiro de 9 passos, que abrange as três etapas descritas acima: Defina o tema; selecione as fontes de informação; delinear a Tarefa; estruturar o Processo; escrever a Introdução; escrever a Conclusão; insira o conteúdo no gabarito; faça os acertos finais; publique a webquest; consultar seções da WQ para ver as partes constituintes de uma Webquest. Todos esses passos são fundamentais para que se construa uma Webquest de qualidade.

\section{Desenvolvimento Prático de uma Webquest em um projeto pedagógico}

Apresenta-se a seguir um exemplo de uma Webquest "Jornal Virtual" que foi utilizada em laboratório de informática como recurso pedagógico no processo de ensinoaprendizagem dos alunos da $6^{\mathrm{a}}$ série de uma escola privada de Uberlândia. A metodologia utilizada baseou-se em alguns conhecimentos prévios dos alunos, onde estes foram valorizados pelo(a) educador(a). A troca de saberes e o trabalho em equipe

2 Senac SP (Webquest) - http://webquest.sp.senac.br/textos/como 
também foi proposto, além de rodas de conversa entre alunos e educador(a), houveram momentos de construção coletiva, o que enfatizou o trabalho colaborativo e sua relevância.

\subsection{Jornal virtual}

O Jornal Virtual foi uma proposta de um projeto realizado com a turma da $6^{\mathrm{a}}$ série de uma escola privada de Uberlândia. Para incrementar o projeto "Jornal" já trabalhado anteriormente em sala de aula o objetivo foi construir uma Webquest com o intuito de tornar a proposta mais atrativa, devido às várias opções que esta atividade didática dispõe, buscou-se então dar continuidade a este tema criando um jornal na Web, ou seja, um jornal virtual. A idéia foi de criá-lo em um editor de texto ou HTML. Como o Word e o Publisher já foram trabalhados em Informática Educativa e os alunos já estavam familiarizados com estas ferramentas, optou-se por elas. Propôs-se então que os alunos criassem um jornal virtual que apresentasse informações da escola, atividades dos alunos e acontecimentos recentes do mundo.

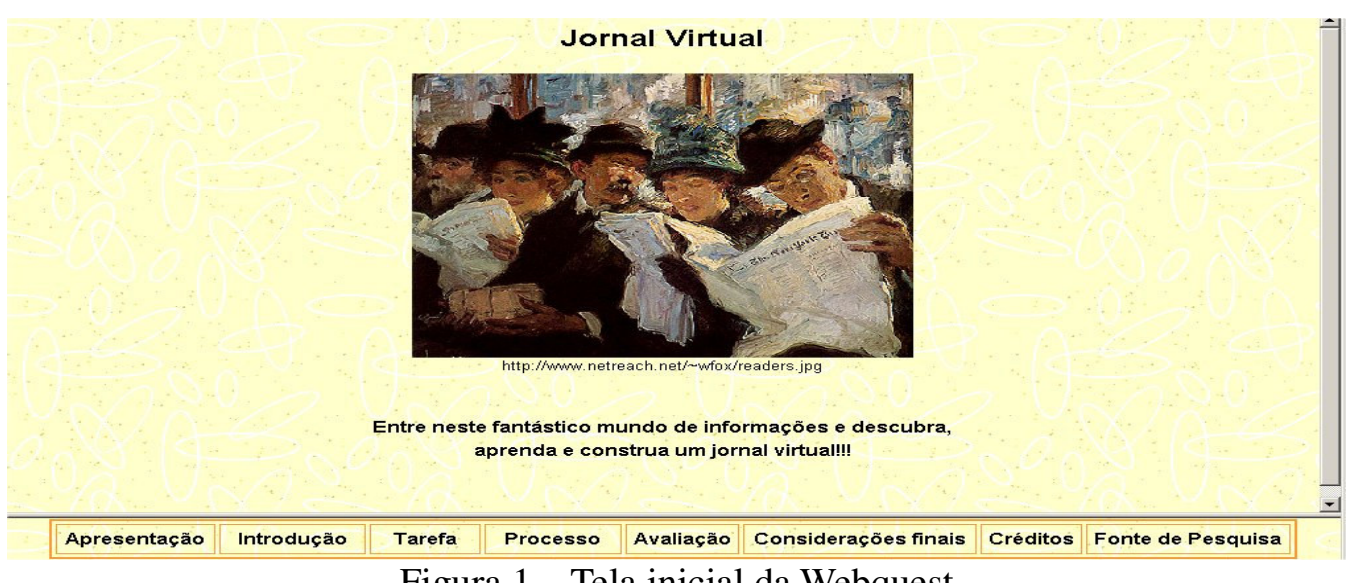

Figura 1 - Tela inicial da Webquest

Fonte: http://www.fernandaquaresma.com.br/site5a8/webquestjornal/jornal.htm

Buscou se acrescentar alguns tópicos além da proposta de Bernie Dodge, alguns dos tópicos são apresentados a seguir: Em Apresentação (figura 1) é informado ao aluno o tema Jornal Virtual, uma imagem relacionada e um chamado para adentrar na Webquest. Esta foi opção da criadora para que ao abrir a Webquest a página principal não fosse diretamente a introdução e sim um tema chamativo. Na Introdução é colocado, de maneira sucinta, como o jornal chega a residência do aluno, algumas de suas páginas como: tirinhas, esporte e astrologia e perguntas que instigassem os alunos a querer respondê-las. Nota-se que as imagens utilizadas são referentes ao conteúdo dos jornais.

$\mathrm{Na}$ Tarefa (Figura 2) o aluno pode verificar qual é a atividade que será realizada, antes mesmo de saber como irá fazê-la. As informações contidas aqui demonstram claramente o que está sendo solicitado a ele e sua equipe. Ao entender isto o aluno começa a refletir sobre como irá realizar esta tarefa e os passos para isto são apresentados no tópico Processo. No Processo optou-se por utilizar desta terminologia para assim além de disponibilizar os recursos que seriam utilizados pelos alunos como os links, apresentar a eles os passos para criação do jornal definidos em etapas. A primeira refere-se a criação das equipes e suas finalidades. A segunda etapa informa como é feita a organização das equipes para a realização de uma visita no jornal da cidade, que materiais irão utilizar e algumas perguntas sugeridas. 

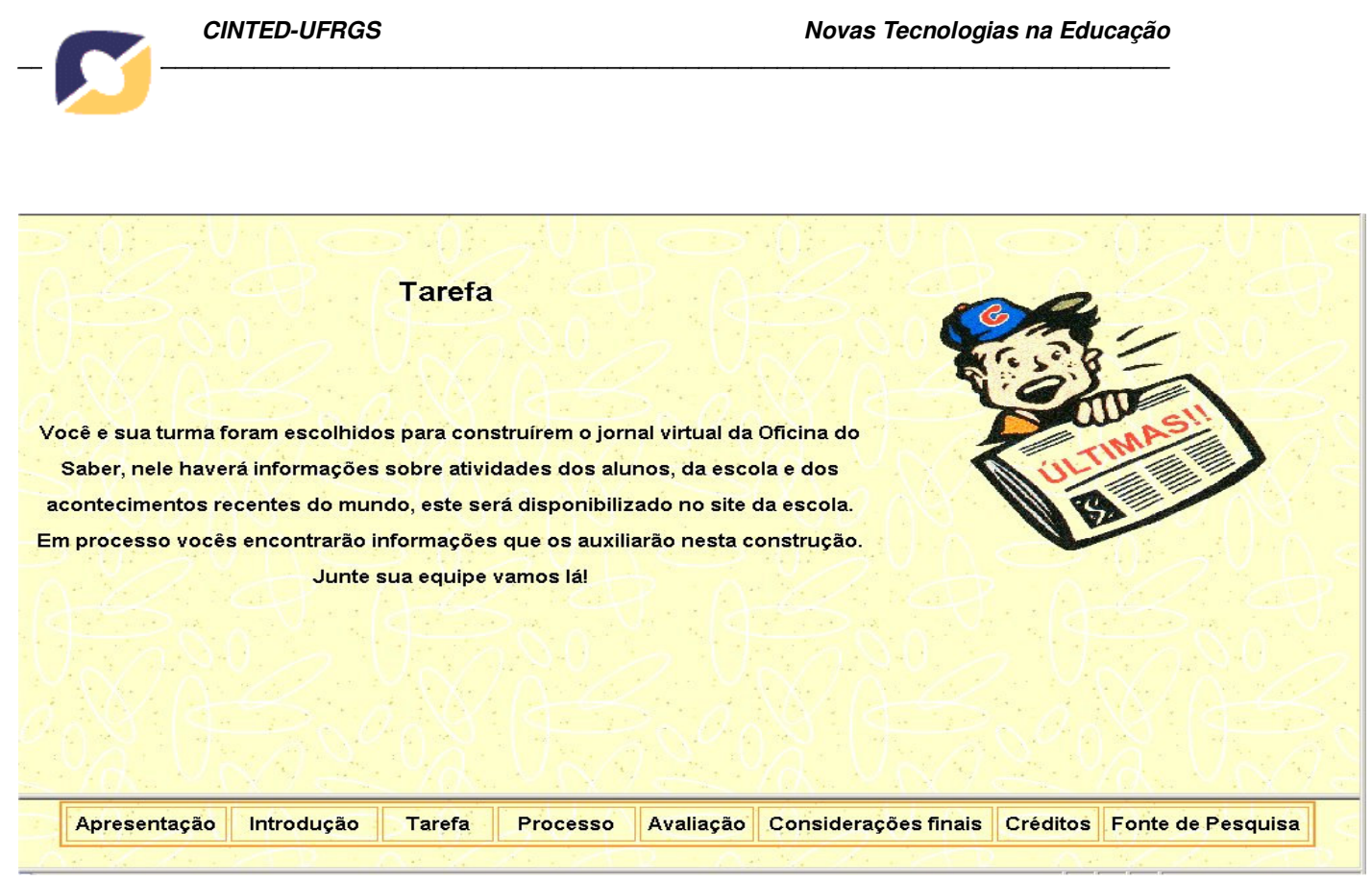

Figura 2 - Tarefa da Webquest

http://www.fernandaquaresma.com.br/site5a8/webquestjornal/jornal.htm

A abordagem sócio-interacionista concebe a aprendizagem como um fenômeno que se realiza na interação com o outro. A aprendizagem acontece por meio da internalização, a partir de um processo anterior, de troca, que possui uma dimensão coletiva. Segundo Vigotsky, a aprendizagem deflagra vários processos internos de desenvolvimento mental, que tomam corpo somente quando o sujeito interage com objetos e sujeitos em cooperação. Uma vez internalizados, esses processos tornam-se parte das aquisições do desenvolvimento. Assim, um processo interpessoal é transformado num processo intrapessoal. (OLIVEIRA, CAPELLO, REGO e VILLARDI, 2004)

A teoria sócio-interacionista tem muito a contribuir nesta etapa da Webquest, o trabalho em equipe e a troca de saberes entre os alunos oportuniza uma aprendizagem muito mais eficiente, visto que eles estarão desenvolvendo suas habilidades sociais. Sendo assim buscou-se realizar a tarefa em grupo e isto é sugerido no tópico processo. Neste tópico é informado como será feita a divisão das equipes e as finalidades de cada uma. Na terceira etapa foram disponibilizados diversos links referentes à criação de um jornal virtual, alguns modelos de jornais virtuais e dois tutorias referentes as ferramentas que serão utilizadas. Estas ferramentas já foram trabalhadas em laboratório de informática, porém acredita-se que é interessante que os alunos tenham acesso aos tutoriais para eventuais dúvidas. Na avaliação (Figura 3) é informado como os alunos serão avaliados. É muito importante que eles saibam quais comportamentos, informações, imagens, recursos e atividades serão observados pelo(a) educador(a) nesta avaliação. De acordo com Guimarães (2005):

(...) o processo de avaliação deve trazer novas oportunidades de aprendizagem, permitindo que o aluno reflita sobre o seu desenvolvimento (auto-avaliação) e, partindo de intervenções externas - do professor - possa ter uma atitude pro-ativa, avançando no seu ciclo de desenvolvimento. (GUIMARAES, 2005) 
Avaliar é muito importante em um processo educativo, mas saber como avaliar é ainda mais relevante. Ao se trabalhar com uma Webquest deve se ter em mente qual será o processo avaliativo utilizado. $\mathrm{O}(\mathrm{A})$ educador(a) não pode deixar que este seja motivo para os alunos sentirem receio, constrangimento e submissão. Deve-se fazer compreender que ele será avaliado para que possa a partir do seu erro reconstruir, refazer ou modificar o que foi trabalhado, melhorando seu desempenho e qualidade da atividade realizada.

O aluno tem de notar que os itens que serão observados na avaliação, são características importantes e que estes podem ser aprimorados. Sendo assim, o processo avaliativo será uma oportunidade de fazer com que o aluno repense a sua atividade e a partir desta reflexão possa aperfeiçoá-la. Nas Considerações Finais são apresentados os objetivos do tema proposto, enfatizando a continuidade da busca pelos alunos referentes ao tema. Optou-se por este conceito por acreditar-se que conclusão refere-se a algo "terminado", tendo como vista que a Webquest é uma atividade didática onde poder-seá utilizar em diversos momentos utilizou-se o conceito apresentado. Os Créditos referem-se à autoria da Webquest e o que motivou esta proposta. Diante da proposta de Bernie, é necessário que também sejam disponibilizadas as referências. Preferiu-se aqui referenciar os links utilizados separadamente, visto que a quantidade tornaria a página créditos muito extensa. Desta forma a construção da Webquest baseou-se na proposta de Dodge, porém com algumas adaptações referentes ao tema e objetivos a serem alcançados pelo(a) educador(a).

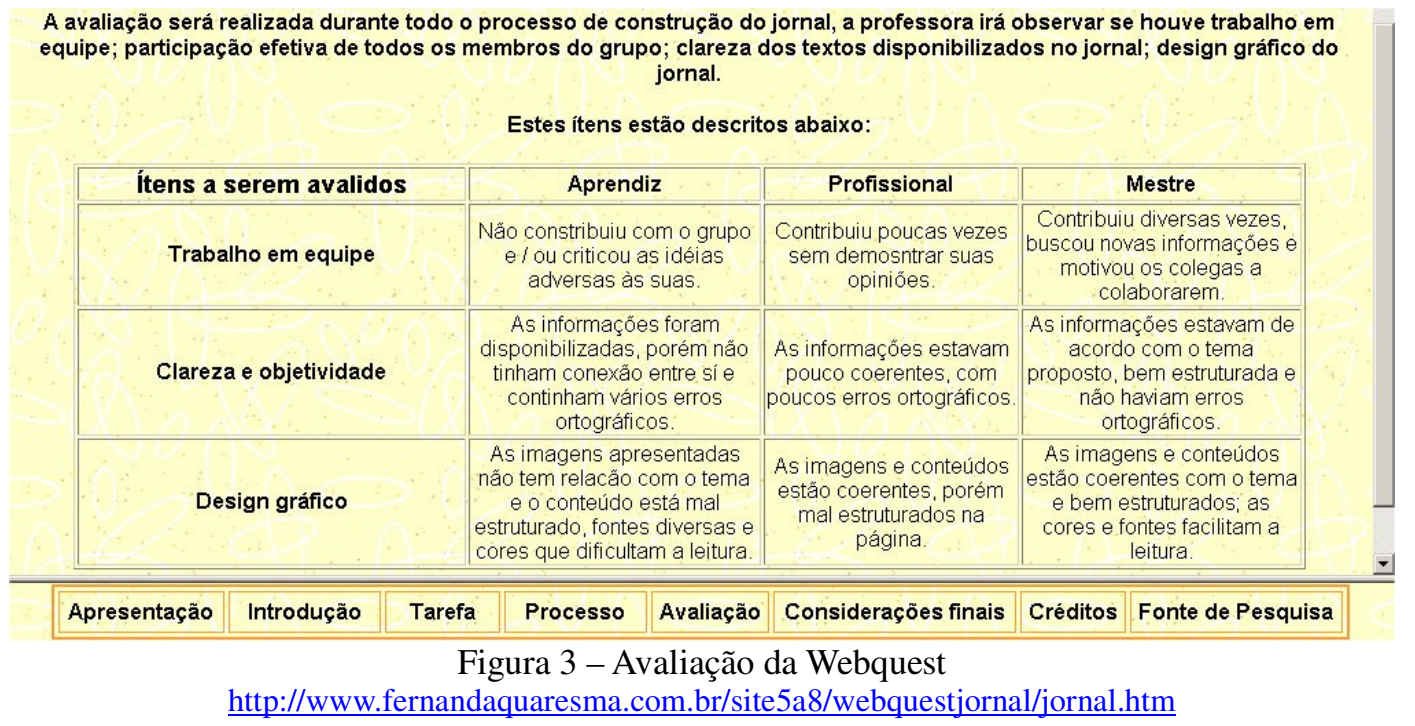

\subsection{Observações da utilização da Webquest pelos alunos}

A partir de observações realizadas junto aos alunos durante o processo de utilização da Webquest relata-se que esta foi a primeira experiência dos alunos de um projeto formulado com uma WQ. Eles puderam perceber que seu uso ultrapassa os limites da escola e que é interessante de se utilizar. Alguns deles tiveram muita dificuldade em se prender a leitura dos tópicos, mesmo que estes estivessem informando os passos para realização da tarefa proposta, o que demonstra mais uma vez o quanto é significativo que ao se trabalhar com a WQ, se tenha em mente que esta deve ser um espaço altamente motivador, criativo e atraente e que projetos de leitura digital podem e devem estar sendo utilizados. A WQ foi revista por eles sempre que demonstravam alguma 
dúvida em relação a criação do jornal. Os links de pesquisa foram os mais utilizados visto que estes embasavam a busca de informações referentes ao tema. Notou-se uma segurança por parte dos alunos ao saberem que sempre que necessário poderiam recorrer a Webquest. Mesmo com a presença da professora percebeu-se que os alunos se sentiram a vontade em trabalhar o tema de forma autônoma, extravasando assim suas idéias e criatividade.

\subsection{Auto-análise da utilização da Webquest pela professora de Informática Educativa}

A Webquest criada e utilizada pela professora foi fator potencializador para alavancar a proposta do projeto trabalhado. Notou-se que esta possibilitou aos alunos um processo autônomo de busca e apropriação do conhecimento. O mais interessante foi perceber que mesmo sem a presença da professora os alunos teriam acesso a Webquest em outros locais que não fosse a escola. Os aspectos mais relevantes da Webquest foram os tópicos que puderam ser adequados ao conteúdo e proposta trabalha. Buscou-se valorizar o trabalho colaborativo a fim de incentivar os alunos na troca de saberes e na participação efetiva de todos. Sendo assim a utilização dos tópicos "Tarefa", "Processo" e "Avaliação" foram cruciais para apresentar aos alunos que o trabalho seria realizado em equipe e que este seria observado para constar na avaliação final. Acredita-se que a Webquest foi construída dentro da proposta de Dodge, onde algumas terminologias mais coerentes com o tema foram utilizadas. Após análise crítica dos conteúdos utilizados percebeu-se que algumas mudanças tornarão a WQ "Jornal Virtual" mais atrativa e interessante, como a Apresentação: esta pode ser mais chamativa, iniciando brevemente o tema de maneira que os alunos queiram adentrar na WQ para saber mais deste tema. Acredita-se também que a utilização de mais imagens nas páginas que compõe a WQ a tornará mais atrativa ao público estudantil. Apesar destas pequenas mudanças a criação desta atividade não teria sido realizada de outra forma, senão esta que foi um grande sucesso nas aulas de informática educativa. Sendo assim, possibilitou que a professora explorasse todas as fontes de informação, imagens e conteúdos diversos que fariam parte da Webquest, criando um ambiente virtual de aprendizagem significativo, criativo e potencializador.

\section{Considerações Finais}

Trabalhar com tecnologias nunca será fácil para educadores que acreditam que o papel do professor deve ser o de transmissor de conhecimento e que os alunos jamais conseguiriam realizar algo sem o seu consentimento, opinião e imposição. Nota-se que nos tempos atuais esse pensamento reducionista já não faz parte e nem cabe mais no contexto educativo. Em roda de conversa realizada com os alunos acerca da utilização da Webquest, estes afirmaram que gostaram de utilizá-la, assim como o computador e internet; relataram que a Webquest facilitou a pesquisa pelo tema e auxiliou no passo-apasso para realização da tarefa. Algumas de suas falas foram: "realizar a tarefa com o uso do computador é mais divertido"; "com a utilização do computador já podem ir treinando a atividade"; "se o conteúdo da Webquest fosse impresso não seria tão utilizado pelas pessoas"; "no computador é direto, faz e já vê o que fez".

Nota-se o quanto nós educadores podemos desenvolver as habilidades cognitivas, sociais e tecnológicas de nossos alunos utilizando as novas tecnologias. Percebe-se que a maneira como utilizam, absorvem informações e percebem o computador é muito mais ampla e desprendida. Esta geração digital consegue expandir 
o uso do computador sem receios, medos ou constrangimento, geração esta que tem muito a nos ensinar. Trabalhar a Webquest foi extremamente gratificante, não apenas pela metodologia Webquest ser uma atividade didática potencializadora da educação, mas também por esta possibilitar um trabalho significativo, construtivo e colaborativo. Sabe-se que o trabalho em grupo onde os alunos colaboram entre si, permite uma aprendizagem muito ampla, onde não só adquirem novos conhecimentos, mas também novas habilidades. Habilidades interpessoais quando interagimos com outro, intrapessoais quando refletimos e adaptamos o que aprendemos com o com a interação com o outro, além de outras habilidades que podem permear essa troca de saberes. Trabalhar projetos que fazem uso do computador muitas vezes torna a proposta mais interessante, criativa e eficaz, principalmente em se tratando de um público jovem e desafiador. Portanto, além de um sentimento de superação, motivação e prazer em trabalhar com tecnologias educativas, desenvolver uma Webquest para promover o conhecimento e autonomia dos alunos foi muito positivo. Espera-se que esta experiência possa desencadear outras propostas semelhantes e que sejam cada vez melhores, abrangendo muito mais do que se propõe.

\section{Referências}

ABAR, Celina A. A. P.; BARBOSA, Lisbete Madsen. Webquest um desafio para o professor: uma solução inteligente para o uso da internet. São Paulo: Avercamp, 2008. 100 p.

ALMEIDA, Ronaldo Garcia. A utilização da informática como recurso pedagógico. Disponível em: < http://vivenciapedagogica.com.br/informaticarecursopedagogico>. Acesso em: 06 out. 2008.

BARROS, Gílian Cristina. Webquest: Metodologia que ultrapassa os limites do ciberespaço. Disponível em:

$<$ http://www.gilian.escolabr.com/textos/webquest_giliancris.pdf>. Acesso em: 25 de out. 2008.

CLUBE DO PROFESSOR. Webquets. Disponível em:

$<$ http://www.clubedoprofessor.com.br/webquest/>. Acesso em: 4 maio 2008.

GUIMARAES, Maria Isabel. Avaliação como oportunidade de aprendizagem.

Disponível em: <http://www.escola2000.org.br/pesquise/texto/textos_art.aspx?id=78>.

Acesso em: 16 nov. 2008.

MASETTO, Marcos T.. Mediação pedagógica e o uso da tecnologia. In:

MORAN, José Manuel; MASETTO, Marcos T.; BEHRENS, Marilda Aparecida. Novas tecnologias e mediação pedagógica. 12 ed. Campinas: Papirus, 2000. p. 11-65.

MEC. Recursos da internet para a educação. Disponível em:

$<$ http://www.webeduc.mec.gov.br/webquest/index.php>. Acesso em: 20 set. 2008.

MORAN, José Manuel. Novas tecnologias e o re-encantamento do mundo.

Disponível em: <http://www.eca.usp.br/prof/moran/novtec.htm>. Acesso em: 15 abr. 2008. 
OLIVEIRA, Eloiza da Silva Gomes; CAPELLO, Cláudia; REGO, Marta Lima; VILLARDI, Raquel. O processo de aprendizagem em uma perspectiva sóciointeracionista...ensinar é necessário, avaliar é possível. Disponível em:

$<$ http://www.abed.org.br/congresso2004/por/htm/171-TC-D4.htm>. Acesso em: 28 out. 2008.

SILVA, Fernanda Quaresma. Webquest Jornal Virtual. Disponível em:

$<$ http://www.fernandaquaresma.com.br/site5a8/webquestjornal/jornal.htm>. Acesso em: Agosto 2008 